\title{
Does modularity of metal-on-metal hip implants increase cobalt: chromium ratio?
}

\author{
Kevin C Ilo, Karim Aboelmagd, Harry S Hothi, Asaad Asaad, John A Skinner, Alister J \\ Hart
}

\begin{abstract}
Background: Blood metal ion levels are used in the surveillance of metal-on-metal (MoM) hip implants. Modular implants contain an extra source of metal debris that may affect the ratio of metal ions in the blood.
\end{abstract}

Methods: This was a retrospective study of 503 patients with hip replacements made by a single manufacturer (Smith \& Nephew, Warwick, UK) with the same bearing surface. There were 54 total hip arthroplasties, 35 Birmingham Mid- Head Resections and 414 hip resurfacings. Whole blood metal ion levels and their ratios were analysed to investigate the effect of a modular junction.

Results: The cobalt:chromium ratios were greater in the total hip arthroplasty group (mean 2.3:1) when compared to the resurfacings group (mean 1.3:1, $p=<0.05$ ) and Birmingham Mid-Head Resection group (mean 1.1:1, $p=0.11$ ). Conclusions: This study demonstrated a trend for a higher cobalt:chromium ratio in patients with MoM total hip replacement that may be due to metal debris from the modular stem-head junction. Further work is required to correlate clinical data with retrieval analysis to confirm the effect of taper material loss on the cobalt:chromium ratio.

\section{Introduction}

Due to its success, the use of total hip arthroplasty (THA) has been extended into younger age groups. In these patients, bone-conserving implants are attractive. Hip resurfacing and midhead resection arthroplasty are good examples. Unfortunately, these require metal-on-metal $(\mathrm{MoM})$ bearings to provide the wear resistance needed. With resurfacings, metal ions are only released from wear at the bearing surface. However, with MoM THA and mid- head resection arthroplasty there is potential metal ion release from wear of the bearing surfaces, ${ }^{1}$ and wear and corrosion at the head-neck taper. ${ }^{2}$ The widespread use of MoM bearings, led to the identification of complications that have resulted in a reduction in the use of MoM implants.

Blood metal ion levels are utilised in the surveillance of patients with MoM implants. ${ }^{3}$ The main source of metal debris is as a result of wear from the articulating bearing surface. Mechanical and corrosive damage at modular junctions have also been shown to be a cause of metal debris formation. 2,4 Blood metal ion levels may provide useful information regarding the production of metal debris in situ. Blood metal ion levels can be affected by various implant and patient factors. 3,5 It has been previously reported that the addition of modular junctions increases blood metal ion levels. 6 Conversely, current interpretation of blood metal ion levels are unable to pro- vide information regarding the integrity of the modular junction. Any information we can gather regarding the in vivo performance of the implant would be beneficial. The aim of this study was to investigate whether modularity leads to a difference in blood metal ion levels and their ratios. 


\section{Methods}

This was a retrospective, non-randomised study performed at a tertiary referral centre for MoM implants. In order to compare the effect of modularity on blood metal ion lev- els, we identified implants from a single manufacturer with the same bearing surface design and metallurgy with and without a modular junction. Smith and Nephew's (Warwick, UK) MoM Birmingham Hip system consists of high carbon content cobalt chrome molybdenum (CoCrMo) alloy bearing surfaces that is utilised as different types of arthroplasty (Figure 1).

The Birmingham Hip resurfacing is a joint resurfacing implant which contains no modular junction. Conversely, the Birmingham Hip total hip arthroplasty has a modular taper junction within the femoral head component which can be used with a variety of femoral stem implants. ${ }^{7} 1$ of these options uses an alternatively designed femoral com- ponent which is positioned within the femoral neck and not the shaft. This bone-conserving arthroplasty is the Birmingham Mid-Head Resection arthroplasty (BMHR).

A total of 503 patients were identified who had under- gone a unilateral hip replacement with a MoM Birmingham Hip bearing system. Patient demographic data and the blood metal ion levels were collected for all implants. Data was collected in the period from July 2009 to May 2013. Of the 503 patients identified with a MoM Birmingham Hip bearing system, there was a total of 414 hip resurfac- ings, 54 THAs and 35 BMHRs.

\section{Statistics}

All statistics were performed using the statistical software package SPSS 22 (Spss Inc., Chicago, Ill). The Mann- Whitney U-test was utilised to determine a significant dif- ference between the different implant groups. A significance level of $p<0.05$ was utilised.

\section{Results}

Amongst the 414 patients with hip resurfacings; 308 had subsequently been revised, whilst 106 had well-functioning implants. The 54 patients with THAs had all been revised, whilst all 35 patients with a BMHR were all well-function- ing. A well-functioning implant was determined clinically as an asymptomatic implant which had no indication for revision (unexplained pain, pseudotumour, loosening etc.) and was purely under surveillance in accordance with Medicine and Healthcare Regulatory Authority (MHRA) guidelines. Patient demographic data is illustrated in Table 1.

Figure 1. Photograph image (100-mm lens) of MMT/Smith \& Nephew metal-on-metal bearing surface utilised as different implants. (A) Birmingham Mid-Head Resection (B) total hip arthroplasty $(\mathrm{C})$ resurfacing.

Reasons for revision are illustrated in Table 2. Whole blood cobalt $(\mathrm{Co})$ and chromium $(\mathrm{Cr})$ levels were collected for all patients. For revised implants the pre-revision blood metal ion results were used and for the well-functioning patients; the most recent result.

\section{Blood metal ions levels and ratios of different implant types}

Blood metal ion levels are illustrated for the different implant types in Table 3, Figures 2 and 3. 
The only statistically significant difference in cobalt levels was between the resurfacings group and the BMHR group $(p=0.0115)$.

The only statistically significant difference in chro- mium levels was between the resurfacings group and the BMHR group $(p=0.0222)$.

The only statistically significant difference in Co:Cr ratio was between the THA group and the resurfacings group $(p=0.0426)$.

\section{Blood metal ion levels and ratios of revised and well-functioning implants}

There was no statistically significant difference between cobalt levels and $\mathrm{Co}: \mathrm{Cr}$ ratios of the THA group (all revised) and the revised Resurfacings group. Although there was a trend for a higher Co:Cr ratio in the THA group (mean 2.3, range 0.6-10) in comparison to the revised Resurfacing group (mean 1.5, range $0-60$ ). The Chromium levels were statistically different ( $p$ $=0.0079)$.

There was no statistically significant difference between chromium, cobalt and Co:Cr ratio of the BHMR group (all well-functioning) and the functioning Resurfacings group.

Comparing all functioning implants with revised implants, revised implants showed statistically significant higher cobalt $(p<0.001)$, chromium $(\mathrm{p}<0.001)$ and $\mathrm{Co}$ :Cr ratios $(p=$ 0.0204).

\section{Discussion}

Modularity of implants permit the use of different compo- nents that allow better replication of individual hip biome- chanics. However, failure of the modular taper junction has become a cause of concern regarding metal ion release with THAs. ${ }^{8-13}$ Metal ions are not inert and can cause an inflammatory reaction which can be both localised and systemic. There are reports of localised lesions which can be destructive and high incidences of unexplained pain. Nonetheless, there have been vast numbers of MoM hip replacements implanted which are under surveillance as advised by the MHRA. The utilisation of blood metal ions provides a marker of the in-vivo performance of MoM bearings but the effect of modularity is unknown. This study aims to further understand blood metal ion levels and their ratios. 3 different implants that have the same bearing surface, with and without a modular junction were included in this study. 2 of these implants had a modular junction (THA, BMHR) whilst the other did not have a modular junction (resurfacings). Analysis of blood metal ions between the implants showed that the resurfacings group had higher individual cobalt and chromium levels, than the other implants. However, the resurfacings blood metal ion levels were only statistically significantly higher than the BMHR group. The ratio of cobalt to chromium was highest in the THA group and this was significantly greater than the resurfacings group. As this was a retrospective study including all implants with the same bearing surface, the different implant groups were not matched demographi- cally or functionally. Some of the implants had subsequently been revised. The THA group had all been revised and therefore their blood metal ion levels were further com- pared to revised resurfacings. The failed resurfacings had a higher Co and $\mathrm{Cr}$ level but the THA group had a higher $\mathrm{Co}: \mathrm{Cr}$ ratio. This was not statistically significant, however there was 1 anamolous result in the failed resurfacing group, which was a Co:Cr ratio of 60. Removing this result from the analysis did result in a significantly greater $\mathrm{Co}: \mathrm{Cr}$ ratio in the THA group when compared to failed resurfac- ings $(p<0.0001)$. The BMHR group were 
all well-functioning and therefore their blood metal ion levels were compared to wellfunctioning resurfacings. There was no difference in $\mathrm{Co}, \mathrm{Cr}$ and $\mathrm{Co}: \mathrm{Cr}$ ratios between the two groups of well-functioning implants. We also compared the functioning implants to the revised implants. This did show significantly greater $\mathrm{Co}, \mathrm{Cr}$ and $\mathrm{Co}$ : $\mathrm{Cr}$ ratio.

There are reports which have not shown $\mathrm{Co}: \mathrm{Cr}$ to be useful, especially for diagnosing adverse local tissue reaction (ALTR). ${ }^{14,15}$ This has been attributed to variabilities in alloy composition, solubility of metal ions and excretion. In this study, we have shown that wellfunctioning implants have lower blood metal ion levels than failed implants with the same bearing surface. However more importantly there was an increase in $\mathrm{Co}: \mathrm{Cr}$ ratio with modularity. There are other studies that have shown elevated Co levels com- pared to $\mathrm{Cr}$ levels in modular implants. ${ }^{14,16-18}$ In a prospective randomised clinical trial, Garbuz et al. ${ }^{18}$ compared clinical outcomes of resurfacings to large diameter head THAs. At 1 year the THA group showed a marked elevation of $\mathrm{Co}$ in relation to $\mathrm{Cr}$ when compared to the resurfacing group. The elevation in the $\mathrm{Co}: \mathrm{Cr}$ ratio may be due to the production of a $\mathrm{Cr}$ oxide passivation layer that develops at the head-neck junction. The consumption of $\mathrm{Cr}$ ions to form the passivation layer could potentially decrease the amount of $\mathrm{Cr}$ ions reaching systemic circulation. Hypothetically, this will increase the Co:Cr ratio.

Metal ion debris is produced from several sources, subsequently their levels are affected by material loss from the bearing surface, taper junction and component impingement. The influence of the taper junction will prove difficult to isolate. In this study, we have investigated implants with the same manufactured bearing surface with and without a modular junction. This study found an increase in $\mathrm{Co}: \mathrm{Cr}$ ratio in the THA group when compared to resurfacings and the BMHR. We may have expected that because the BMHR also has a modular junction the Co:Cr ratio should be increased. However, the tapers of the BMHR and the THA are different. The BMHR has a collar just below the taper for the head to sit on, which the THA doesn't. This could protect this taper from fluid and debris that can exacerbate corrosive material loss at this junction. Also, due to the geometry of the BMHR implant the forces that act through this are similar to a resurfacing and the implant is well supported by the native femoral neck. In contrast the THA undergoes forces, which are transferred through the implant and the unsupported taper junction allowing the potential for micro-movement that exacerbates corrosion at the taper junction. ${ }^{19}$

Moharrami et al. 20 showed that the oxide layer produced by the titanium alloy (commonly used in femoral stems) was both harder and thicker than the oxide layer produced from the $\mathrm{CoCr}$ alloy. This difference in hardness causes abrasive wear of the female $\mathrm{CoCr}$ taper resulting in wear debris and ion release. As the $\mathrm{Cr}$ ions are utilised in the formation of the passivation layer this would lead to an increase in Co with a lesser increase in Cr. In this study, all groups utilised the same bearing surface design and metallurgy, therefore the increase in Co ions greater than $\mathrm{Cr}$ ions in the THA group is possibly due to release from the taper head-neck junction. Clinically there has been a significant difference regarding the performance of the Birmingham Hip Resurfacing and the Birmingham THA. In this study there was a higher incidence of ALTR in the failed THA group when compared to the failed resurfacings. Data from the national joint registries of Australia and England and Wales have shown that revision rates are higher for the Birmingham THA when compared to other conventional hip replacements. 21 However, the Birmingham resurfacing has a much lower revision rate and performs well when compared to other resurfacings. As both implants utilise the same bearing surface, the issue may result from the taper junction. There are a range of conventional stems 
that can be and are used with the Birmingham Hip modular head. This mixing and matching of components could be the underlying issue. Unfortunately, in this study information regarding the different stems used was not available.

Addition of another metal-metal interface leads to corrosion related complications, especially when differing metals are combined. 17,18 Collier et al. ${ }^{22}$ looked at the taper interface between 139 modular femoral components. In 91 femoral head and stem couples the same alloy was used and none of the implants examined in this group showed evidence of corrosion. Of the 48 implants that utilised a titanium stem with a $\mathrm{CoCr}$ head, 25 showed evidence of corrosion. 22 The mixing of metals in THA is 1 of the factors that contribute to corrosion at the taper junction as this can permit galvanic corrosion. Although the material loss at the junction is relatively small as shown in a study by Matthies et al. ${ }^{2}$, the relative greater increase in Co rather than $\mathrm{Cr}$ may give an insight into the integrity of the taper junction. Cooper et al. ${ }^{23}$ reported on 10 patients with metal-on-polyethylene bearings who underwent revision for symptoms including pain, instability and swelling. Co levels were found to be higher than $\mathrm{Cr}$ levels and it was concluded that corrosion at the head neck taper can cause adverse local tissue reactions. ${ }^{23}$ This suggests that $\mathrm{Co}: \mathrm{Cr}$ ratio could potentially aid in discovering whether the culprit of problematic metal debris is from the bearing surface or the modular junctions. However, cobalt is more soluble than chromium, therefore cobalt is more readily dissolved into the blood and this may affect the Co:Cr ratio. If this proves to be the case, then it questions whether a well- fixed stem should be revised if the Co:Cr ratio suggests that the modular junction is a cause for concern.

Blood metal ion levels play an important role in the surveillance of MoM implants. The MHRA have suggested a threshold of $7 \mathrm{ppb}$, above which suggests possible further investigations for the symptomatic patients. ${ }^{24}$ However, blood metal ions below this threshold does not fully equate to a well-functioning implant. In this study, we have shown that in failed retrievals there are a large number below this level. The increase of Co and $\mathrm{Cr}$, especially in implants with a modular junction does not appear to be equal. In modular implants, it appears that the Co increases more than $\mathrm{Cr}$ and this may be due to the taper junction. The $\mathrm{Co}: \mathrm{Cr}$ ratio could possibly be used to risk stratify implants that undergo taper failure. Therefore, a possible alteration to the reporting of clinical reference levels used to monitor patients with implants that contain Co and $\mathrm{Cr}$ levels, could possibly include a $\mathrm{Co}$ :Cr ratio. The threshold of $7 \mathrm{ppb}$ for $\mathrm{Co}$ and $\mathrm{Cr}$ levels set by the MHRA may need to be augmented for modular implants to acknowledge the influence of the taper junctions.

\section{Limitations}

We acknowledge that there are several limitations to this study. This study has investigated different groups of patients that have not been demographically matched which can introduce confounding factors to our results. Patient factors such as kidney function, occupational exposure and dietary supplementation were not identified. In this study, there were no wellfunctioning THAs and failed BMHR to compare results to. The cause of failure was not determined for every implant and possibly could affect the blood metal ion levels, such as component impingement. The analysis of blood metal ion levels was performed at different laboratories that can introduce measurement differences. In our group of failed THAs there was a number of various stems used which will affect the geometry and characteristics of the modular taper junction. Unfortunately, not all stems could be identified as some stems were well fixed and left in situ, therefore not revised. 


\section{Conclusion}

The full significance of blood metal ion levels and their correlation with the in-vivo performance of MoM bearings are not fully known. There are a large number of MoM bearings, which have failed with blood metal ion levels less than 7ppb. However, until more is known about the significance of blood metal ion levels, we cannot advise on how this value should be altered. This study, which focused on implants with the same metallurgy, showed a trend of higher Co:Cr ratio in patients with a MoM THA that may be attributed to metal debris from the modular stem-head junction. Further work is required to correlate retrieval analysis with blood metal ions to investigate the effect of material loss from modular junctions on blood metal ions and ratios.

\section{References}

1. Hart AJ, Muirhead-Allwood S, Porter M, et al. Which factors determine the wear rate of large-diameter metal- on-metal hip replacements? Multivariate analysis of two hundred and seventy-six components. J Bone Joint Surg Am 2013; 95: 678-685.

2. Matthies AK, Racasan R, Bills P, et al. Material loss at the taper junction of retrieved large head metal-on-metal total hip replacements. J Orthop Res 2013; 31: 1677-1685.

3. Hart AJ, Sabah SA, Sampson B, et al. Surveillance of patients with metal-on-metal hip resurfacing and total hip prostheses: a prospective cohort study to investigate the relationship between blood metal ion levels and implant failure. J Bone Joint Surg Am 2014; 96: 1091-1099.

4. Kretzer JP, Jakubowitz E, Krachler M, et al. Metal release and corrosion effects of modular neck total hip arthroplasty. Int Orthop 2009; 33: 1531-1536.

5. Amstutz HC, Campbell PA, Dorey FJ, et al. Do ion con- centrations after metal-onmetal hip resurfacing increase over time? A prospective study. J Arthroplasty 2013; 28: 695-700.

6. Johnson AJ, Le Duff MJ, Yoon JP, et al. Metal ion levels in total hip arthroplasty versus hip resurfacing. J Arthroplasty 2013; 28: 1235-1237.

7. Arirachakaran A, Sukthuayat A, Sisayanarane T, et al. Platelet-rich plasma versus autologous blood versus steroid injection in lateral epicondylitis: systematic review and net- work meta-analysis. J Orthop Traumatol 2016; 17: 101-112.

8. Krishnan H, Krishnan SP, Blunn G, et al. Modular neck femoral stems. Bone Joint J 2013; 95-B: 1011-1021.

9. Sotereanos NG, Sauber TJ and Tupis TT. Modular femo- ral neck fracture after primary total hip arthroplasty. J Arthroplasty 2013; 28: 196.e7-e9.

10. Hothi HS, Matthies AK, Berber R, et al. The reliability of a scoring system for corrosion and fretting, and its rela- tionship to material loss of tapered, modular junctions of retrieved hip implants. J Arthroplasty. Epub ahead of print 10 December 2013. DOI: 10.1016/j.arth.2013.12.003. 
11. Cooper HJ, Urban RM, Wixson RL, et al. Adverse local tis- sue reaction arising from corrosion at the femoral neck-body

12.Higgs GB, Hanzlik JA, MacDonald DW, et al. Is increased modularity associated with increased fretting and corrosion damage in metal-on-metal total hip arthro- plasty devices?: a retrieval study. J Arthroplasty 2013; 28(Suppl. 8): 2-6.

13. Vundelinckx BJ, Verhelst LA and De Scheppe J. Taper corrosion in modular hip prostheses: analysis of serum metal ions in 19 patients. J Arthroplasty 2013; 28: 12181223.

14. Fehring TK, Carter JL, Fehring KA, et al. Cobalt to chro- mium ratio is not a key marker for adverse local tissue reac- tion (ALTR) in metal on metal hips. $J$ Arthroplasty 2015; 30(Suppl. 9): 107-109.

15. Persson A, Eisler T, Bodén H, et al. Revision for sympto- matic pseudotumor after primary metal-on-polyethylene total hip arthroplasty with a standard femoral stem. $J$ Bone Joint Surg Am 2018; 100: 942-949.

16. Doherty AT, Howell RT, Ellis LA, et al. Increased chro- mosome translocations and aneuploidy in peripheral blood lymphocytes of patients having revision arthroplasty of the hip. J Bone Joint Surg Br 2001; 83: 1075-1081.

17. Kop AM and Swarts E. Corrosion of a hip stem with a modular neck taper junction: a retrieval study of 16 cases. J Arthroplasty 2009; 24: 1019-1023.

18. Goldberg JR, Gilbert JL, Jacobs JJ, et al. A multicenter retrieval study of the taper interfaces of modular hip pros- theses. Clin Orthop Relat Res 2002; (401): 149-161.

19. Higgs GB, Hanzlik JA, MacDonald DW, et al. Is increased modularity associated with increased fretting and corrosion damage in metal-on-metal total hip arthroplasty devices?: a retrieval study. $J$ Arthroplasty 2013; 28: 2-6.

20. Moharrami N, Langton D, Sayginer O, et al. Why does titanium alloy wear cobalt chrome alloy despite lower bulk hardness: a nanoindentation study? Thin Solid Films 2013; 549: 79-86.

21. The Australian Orthopaedic Association National Joint Replacement Registry. 2013 Annual report, https:/aoanjrr. dmac.adelaide.edu.au/documents/10180/127202/Annual Report 2013?version=1.2\&t=1385685288617 (2013, accessed 05 August 2018).

22. Collier JP, Surprenant VA, Jensen RE, et al. Corrosion between the components of modular femoral hip prostheses. J Bone Joint Surg Br 1992; 74: 511-517.

23. Cooper HJ, Della Valle CJ, Berger RA, et al. Corrosion at the head-neck taper as a cause for adverse local tissue reactions after total hip arthroplasty. J Bone Joint Surg Am 2012; 94: 1655-1661. 
24. Hart AJ, Sabah SA, Bandi AS, et al. Sensitivity and speci- ficity of blood cobalt and chromium metal ions for predict- ing failure of metal-on-metal hip replacement. $J$ Bone Joint Surg Br 2011; 93: 1308-1313.

\section{Figures}

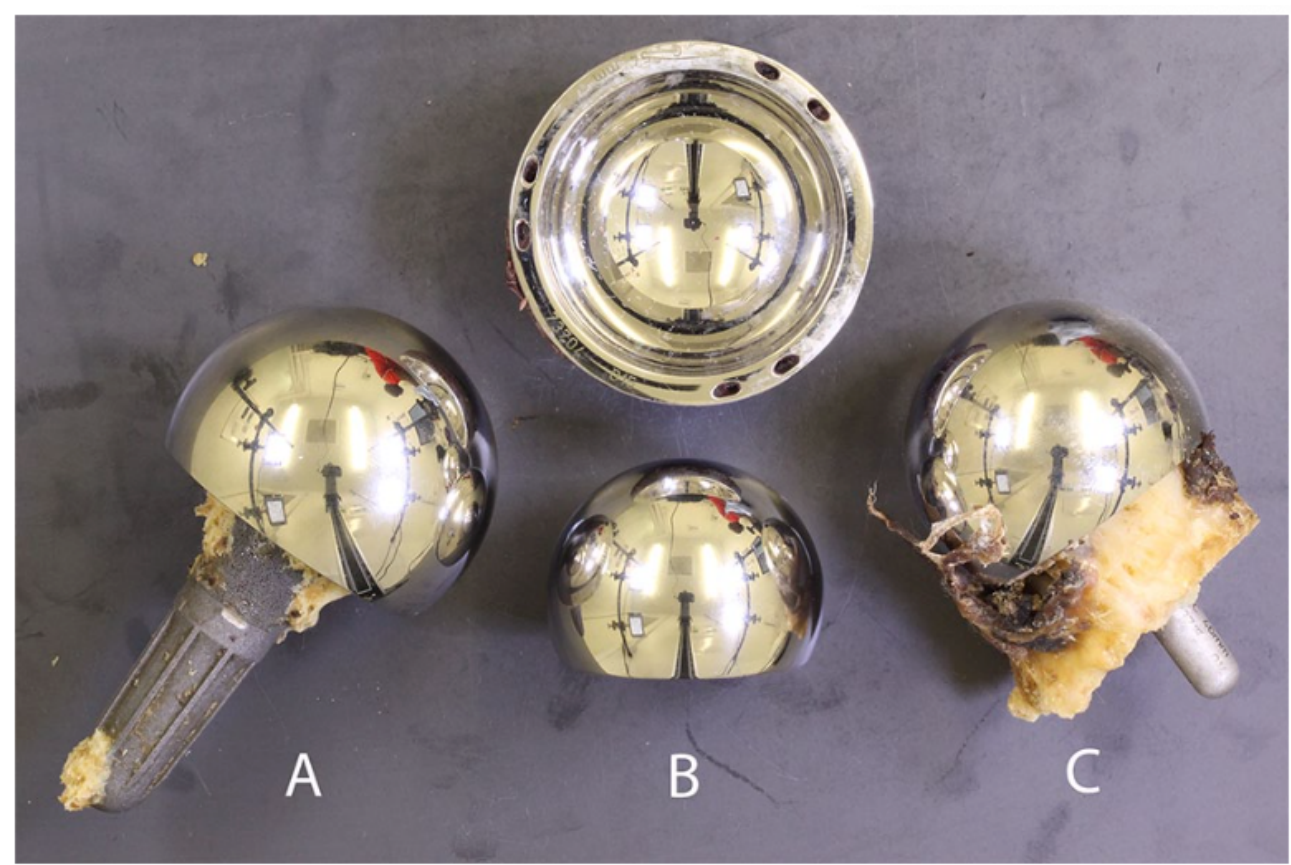

Figure 1. Photograph image (100-mm lens) of MMT/Smith \& Nephew metal-on-metal bearing surface utilised as different implants. (A) Birmingham Mid-Head Resection (B) total hip arthroplasty $(\mathrm{C})$ resurfacing. 


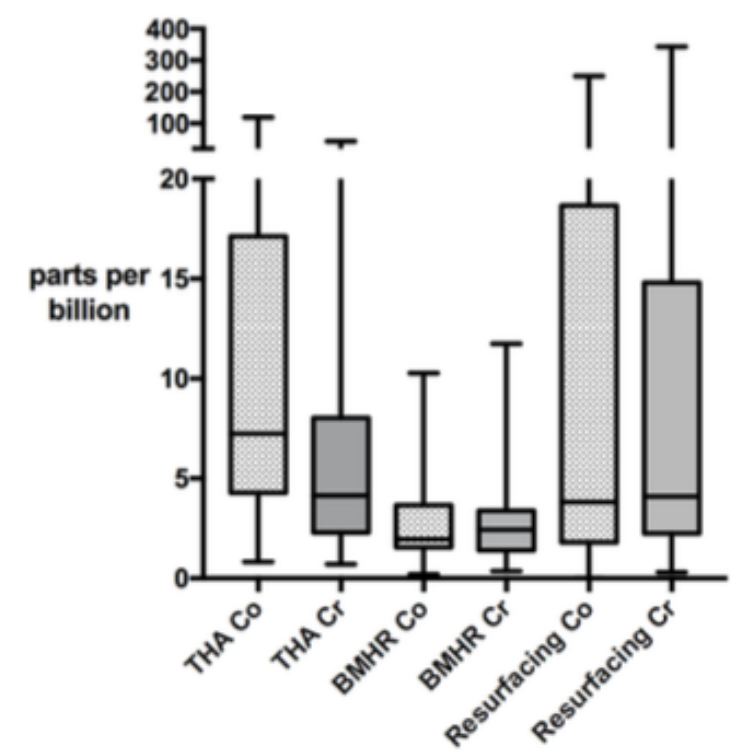

Figure 2. Graph illustrating blood metal ion levels of different implant types.

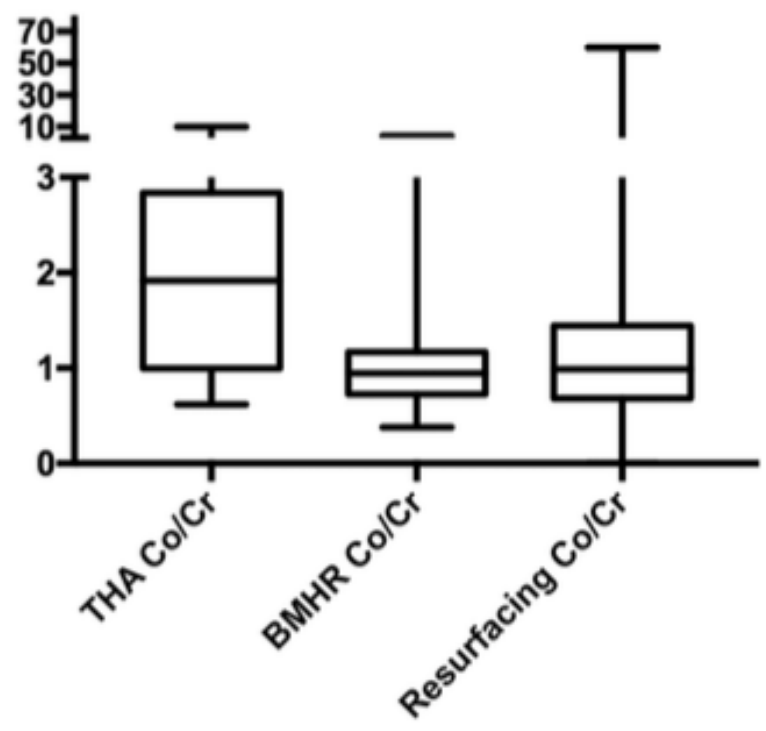

Figure 3. Graph illustrating Co:Cr ratio of different implant types. 
Table I. Patient demographic data for implant groups.

\begin{tabular}{|c|c|c|c|c|c|c|c|}
\hline \multirow[t]{2}{*}{ Implant } & \multirow[t]{2}{*}{$M: F$} & \multicolumn{2}{|c|}{ Age (years) } & \multicolumn{2}{|c|}{ Head size $(\mathrm{mm})$} & \multicolumn{2}{|c|}{ Time in situ (mths) } \\
\hline & & Median & Range & Median & Range & Median & Range \\
\hline $\begin{array}{l}\text { THA } \\
(n=54)\end{array}$ & $25: 29$ & 69 & $39-84$ & 46 & $38-58$ & 53 & $11-128$ \\
\hline $\begin{array}{l}\text { BMHR } \\
(n=35)\end{array}$ & $20: 15$ & 56 & $30-71$ & 48 & $44-56$ & 73 & $37-92$ \\
\hline $\begin{array}{l}\text { Resurfacing } \\
(n=4 \mid 4)\end{array}$ & $219: 95$ & 68 & $26-84$ & 48 & $38-54$ & 140 & $5-158$ \\
\hline
\end{tabular}

Table 2. Reasons for implant revision.

\begin{tabular}{|c|c|c|c|c|c|c|c|c|}
\hline $\begin{array}{l}\text { Revised } \\
\text { Implant }\end{array}$ & $\begin{array}{l}\text { Unexplained } \\
\text { pain }\end{array}$ & $\begin{array}{l}\text { Aseptic } \\
\text { loosening }\end{array}$ & Infection & Psuedotumour & Instability & High metal ions & Fracture & Impingement \\
\hline $\begin{array}{l}\text { THA } \\
(n=54)\end{array}$ & 25 & 5 & 4 & 19 & 1 & - & - & - \\
\hline $\begin{array}{l}\text { Resurfacing } \\
(n=308)\end{array}$ & 142 & 34 & 10 & 49 & 7 & 41 & 14 & 11 \\
\hline
\end{tabular}

Table 3. Blood metal ion levels and ratios of different implant types.

\begin{tabular}{|c|c|c|c|c|c|c|c|c|c|}
\hline \multirow[t]{2}{*}{ Implant Type } & \multicolumn{3}{|c|}{ Cobalt (ppb) } & \multicolumn{3}{|c|}{ Chromium (ppb) } & \multicolumn{3}{|c|}{ Ratio } \\
\hline & Min & Mean & $\operatorname{Max}$ & Min & Mean & Max & Min & Mean & $\operatorname{Max}$ \\
\hline THA & 0.83 & 15 & 119 & 0.7 & 7.8 & 43 & 0.62 & 2.3 & 10 \\
\hline BMHR & 0.18 & 2.8 & 10 & 0.36 & 3 & 12 & 0.38 & I.I & 4.4 \\
\hline Resurfacings & 0 & 19 & 250 & 0.3 & 16 & 343 & 0 & 1.3 & 60 \\
\hline
\end{tabular}

